\title{
Aspectos Legais da Agressividade nas Epilepsias
}

\author{
Carlos José Reis de Campos* \\ Ivette Catarina Jabour Kairalla*
}

\begin{abstract}
RESUMO
Para muitas pessoas com epilepsia, conviver com os estigmas que envolvem tal distürbio é mais dificil que viver com as limitaçōes impostas pelas crises ou pelo tratamento. No presente estudo, os autores analisam aspectos clínicos e jurídicos dos atos de agressividade do paciente epiléptico, buscando oferecer uma contribuiçăo para o diagnóstico mais preciso. para atenuar os aspectos estigmatizantes.
\end{abstract}

\section{UNITERMOS}

Epilepsias, agressividade, aspectos legais.
- Professor-Adjunto Doutor - Chefe do Setor de Investigaçāo e Tratamento das Epilepsias (SITE) da Universidade Federal de Săo Paulo - Escola Paulista de Medicina (UNIFESP. EPM), Brasil.

** Médica Psiquiatra, Mestre em Neurociências pela UNIFESP e Doutoranda em Psiquiatria no Departamento de Psiquiatria e Psicologia Médica da UNIFESP - Programa de Esquizofrenia (Proesq) e do SITE da UNIFESP-EPM.
As epilepsias são muito comuns e, embora na maioria das vezes não tragam incapacidade para seu portador quando estão sob controle, podem, em algumas ocasiões, acarretar problemas de âmbito social, inclusive com risco de vida para o paciente ou para terceiros, quando ocorre uma alteração do nível de consciência, mesmo que com poucos segundos de duração.

Além disso, como se sabe, trata-se de um quadro clínico que apresenta etiopatogenia multifatorial, atingindo regiões cerebrais diversas, o que ocasiona tipos de crises de características variadas quanto à patoplastia e evolução dos sintomas, motivo pelo qual são designadas genericamente no plural (as epilepsias).

Para muitas pessoas com epilepsia, conviver com os estigmas que envolvem tal distúrbio é mais difícil que viver com as limitações impostas pelas próprias crises ou por seu tratamento'.

Vivemos por séculos de estigmatização e ainda nos deparamos com resquícios de muitos dos preconceitos e generalizações. Nos Estados Unidos da América (EUA), por exemplo, até recentemente, 17 estados proibiam pessoas epilépticas de se casar (o último estado a abolir essa lei o fez em 1980). Em 1956, 18 estados tinham estatutos que recomendavam a esterilização eugênica de pessoas com epilepsia ${ }^{1}$.

A situação não era melhor em outros países. No Reino Unido, uma lei proibindo o casamento de pessoas com epilepsia só foi abolida em $1970^{2}$. McLin \& Boer ${ }^{1}$ citavam, ainda, que, em algumas partes do mundo, a epilepsia era comumente considerada como uma razão para anulação de casamento e que, naquela época, em algumas áreas dos EUA, uma adoção poderia ser anulada se a criança, mais tarde, desenvolvesse epilepsia.

Num parecer judicial de 1987, a Suprema Corte dos EUA escreveu que "uma revisão da história da epilepsia fornece um evidente exemplo de que o medo, mais que as limitações por si mesmas, é o maior promotor da discriminação contra as pessoas com deficiência". Hoje as leis federais proíbem a discriminação com base na percepção de uma condição de deficiência, mais que na inabilidade real por si mesma. Naquele país, a primeira lei federal que proibiu discriminação contra pessoas com inabilidades físicas foi o Rehabilitation Act, de 1973. Isso, contudo, ficou limitado em extensão, e foi só em 1990, com o Americans with Disabilities Act, que uma legislação federal conseguiu promover um tratamento mais uniforme e de longo alcance contra a discriminação persistente. 
Até os anos 70, era também legal, na maioria dos EUA, negar acesso, a pessoas com crises epilépticas, a restaurantes, teatros, centros recreativos e outros logradouros públicos' .

O Código Penal Brasileiro, em seu artigo 26, discute a "Inimputabilidade em razão de uma anomalia psíquica: é isento de pena o agente que, por doença mental ou desenvolvimento mental incompleto ou retardado, era, ao tempo da ação ou da omissão, inteiramente incapaz de entender o caráter ilícito do fato ou de determinar-se de acordo com esse entendimento". A imputabilidade de um delito a um paciente epiléptico dependerá do nível de consciência e da vontade dele na hora do ato.

Embora não exista legislação brasileira específica relativa a crimes praticados por pacientes epilépticos, o tema "crime e epilepsia" apresenta-se com muita freqüência na jurisprudência de nosso país, onde se podem encontrar exemplos como os seguintes:

Medida de Segurança: Internação em manicômio judiciário - Imposição a portador de "epilepsia psíquica", autor de homicídio qualificado e de ocultação de cadáver. Parecer apoiado em perícia médicopsiquiátrica que considerou o réu ser portador de personalidade psicopática, do tipo epileptóide.

Polícia Militar - Reforma - Admissibilidade: Autor portador de epilepsia - Incapacidade definitiva para o serviço militar na ativa, ainda que em funções internas (situação imposta é vexatória, uma vez que o recorrente está impossibilitado de participar das atividades inerentes à função) - Ação procedente.

No primeiro exemplo (Medida de Segurança), observamos que, se não se condena o indivíduo à prisão carcerária (que tem duração da pena delimitada), é ele condenado a uma "prisão" manicomial, por tempo indeterminado, a priori, o que lhe tolherá indefinidamente a liberdade.

Nos tribunais ingleses, consideravam-se dois tipos de automatismos: o "insano", atribuído a "fatores internos", como a enfermidade mental, admitindo-se o paciente não culpado, mas encaminhando-o para internação psiquiátrica por tempo ilimitado e alta a ser decidida por tribunais. E o "não-insano", que se atribuía a "fatores externos" (trauma craniano, medicamentos) que resultava em absolvição. Um exemplo clássico é o caso Sulivan, que, em 1983, foi considerado, a princípio, um "automatismo insano" por seu ato agressivo contra um vizinho. Mas, diante da internação indefinida, ele próprio se declarou culpado, obtendo a pena de 3 anos $^{3}$. Horcajadas et al. ${ }^{3}$ comentam, ainda, outras sentenças judiciais duvidosas.

Dentre os aspectos legais referentes aos pacientes epilépticos, têm sido especialmente discutidos os atos de agressividade contra terceiros.
A tendência a relacionar atos de agressividade em pacientes epilépticos já vem de longa data. Têm-se publicado diversos estudos vinculando condutas violentas às epilepsias, principalmente com crises do tipo "temporal", assim como têm sido motivo de debates frequientemente polêmicos em psiquiatria.

Diversos autores referem-se a índices de ocorrência de crises de agressividade em pacientes epilépticos. Como se pode perceber a seguir, essas porcentagens diferem amplamente, quer por diferenças nos tipos de epilepsia, quer por diferenças metodológicas, ou por diferenças nas características de personalidade desses pacientes, as quais, em geral, não são discutidas.

Manzano et $a l .{ }^{4}$, analisando a freqüência de agressividade em pacientes com epilepsia do lobo temporal segundo diferentes autores, referem que: Gastaut (1955) relatou crises de agressividade em 50\% de uma amostra de pacientes com epilepsia do lobo temporal, enquanto Bringley (1957) encontrou $17 \%$, Currie et al. (1971), 7\%, e Falconer (1973), 27\%.

Rodin ${ }^{5}$ registrou $4,8 \%$ de casos de agressividade entre pacientes epilépticos, sem relação com tipos de crises, mais em pacientes jovens, com QI médio-inferior, com mais dano cerebral, mais transtornos psiquiátricos concomitantes e história prévia de distúrbio de conduta.

Gunn $^{6}$ e Herzberg \& Fenwick ${ }^{7}$ apontam algumas explicações para a associação de epilepsia e condutas antisociais:

1. os atos agressivos podem fazer parte das crises,

2. ambas se devem à disfunção cerebral,

3. a epilepsia pode associar-se a quadros psicóticos e afetivos,

4. influências ambientais e socioeconômicas,

5. condutas anti-sociais levam a situações que possibilitam trauma craniano e epilepsia secundária.

Tem sido encontrado maior índice de atos agressivos em pacientes epilépticos com baixo nível intelectual ou outros transtornos neurológicos ${ }^{6,7,8}$.

A literatura em geral distingue três diferentes tipos, em potencial, de comportamentos violentos relacionados à epilepsia: agressão ictal, que ocorre durante a crise, ou o próprio ictus; agressão pós-ictal, no período iminentemente após a crise; e agressão interictal, entre as atividades críticas?

A agressão pós-ictal é mais comum. A violência ictal parece ocorrer numa minoria de epilépticos, geralmente homens jovens, com baixo QI, transtornos prévios de personalidade, história de epilepsia grave e de início precoce, com déficit neurológico ou transtornos psiquiátricos associados, com distúrbio de conduta de longa evolução, traumatismos cranioencefálicos prévios, alterações neurológicas e neurorradiológicas ${ }^{3}$. 
No Workshop Internacional sobre Epilepsia e Agressão $^{8}$, realizado em Bethesda, EUA, em março de 1980 , discutiu-se amplamente essa questão. Até aquela data, registraram-se apenas 15 casos judiciais nos Estados Unidos, nos quais a epilepsia havia sido usada como defesa contra acusação de assassinato, homicídio nãointencional ou distúrbios de conduta. Os automatismos epilépticos haviam sido usados como parte da "responsabilidade legal diminuída" ou "insanidade", que serviram de defesa nesses casos. Nesse encontro internacional, foram apresentados os resultados de um estudo multicêntrico, que incluiu 16 programas de epilepsia dos Estados Unidos, Canadá, Alemanha, Itália e Japão. De um grupo de 5.400 pacientes epilépticos, foram selecionados 19 pacientes que apresentavam comportamento agressivo durante as crises, tendo sido estudadas 33 crises apresentadas por esses 19 pacientes durante esse workshop fechado, com o uso de gravações das crises em video-tape e assistidas em circuito-fechado de TV, além da presença constante de enfermagem durante todos os episódios críticos. Nesse workshop, foram diferenciados os termos "agressão" e "violência", em que a agressão pode ser caracterizada por atos perseverativos e estereotipados, sem qualquer direcionamento a um alvo definido, enquanto a violência implica no ato dirigido a um objeto-alvo (uma pessoa ou objeto inanimado). Ambos referem-se à força física extrema, que resultaria em lesão, destruição ou abuso. Foi utilizada uma escala para a análise dos comportamentos agressivos registrados. Os atos agressivos eram estereotipados, simples, insustentáveis e nunca apoiados em alguma seqüência de movimentos propositais.

Delgado-Escueta et al. ${ }^{8}$ mostraram ser extremamente rara a agressão dirigida durante as crises epilépticas e a conseqüente dificuldade de cometer um assassinato ou homicídio durante um automatismo psicomotor não-dirigido. A análise desses autores mostra que 3 dos 5 pacientes que tinham uma história de graves atuações eram mentalmente retardados ou tinham déficits neurocognitivos.

A agressão tem sido também descrita como parte de uma "síndrome de comportamento interictal", que inclui, entre outras características, emotividade intensa com choro e tristeza, preocupações religiosas e escrita excessiva ${ }^{10}$.

Mendez et al. ${ }^{11}$ também citaram como raros os episódios de agressividade ictal e, quando ocorrem, são súbitos, estereotipados, com amnésia posterior, nunca premeditados e sem que existam tentativas para ocultar o fato. Às vezes podem estar relacionados com a ingestão de álcool. O roubo é semelhante à cleptomania, com características compulsivas, imotivado e, em geral, o paciente não tenta se justificar.
Fenwick ${ }^{12}$ sugere que, se alguém interferir com um paciente no estado de confusão pós-ictal, ele pode se ressentir e reagir tentando empurrar ou atacar o intruso.

Entretanto, em outros estudos não se encontraram taxas aumentadas de agressão em pessoas com epilepsia e, mais especificamente, em pessoas com crises parciais complexas ${ }^{9}$. Apesar da tendência a um comportamento agressivo, a prevalência real para violência relacionada à epilepsia é bastante baixa ${ }^{8}$.

Tem-se procurado estabelecer critérios para buscar uma associação entre epilepsia e atos agressivos ou anti-sociais.

Fenton ${ }^{13}$, Delgado-Escueta et al. ${ }^{8}$ e Hindler ${ }^{14}$ relacionaram critérios para atribuir um delito a um ataque epiléptico. Se se cumprem esses critérios, pode-se conseguir um atenuante ou eximir o paciente de culpa.

Fenton ${ }^{13}$ assinalou os seguintes pontos:

- História anterior de crises.

- História de comportamentos anormais repentinos, de curta duração (minutos) e não-apropriados às circunstâncias.

- Amnésia para os acontecimentos de até um minuto antes.

- Alteração do nível de consciência detectada por outra pessoa, com movimentos inapropriados, desconexão do ambiente, caminhar sem sentir, expressão aturdida. Às vezes há pequenas tentativas de ocultar o crime.

Delgado-Escueta et al. ${ }^{8}$ destacam:

- Um diagnóstico de epilepsia por um especialista competente na matéria.

- O automatismo deve estar documentado pela história, por um circuito-fechado de TV e por monitorização com EEG.

- A agressão durante o automatismo deve ser verificada em gravação de vídeo com um padrão EEG compatível.

- $O$ ato agressivo deve ser característico de ataques habituais segundo a história clínica.

- Julgamento clínico de um especialista sobre a possibilidade de que o ato seja parte do ataque.

Hindler ${ }^{14}$ cita:

- História de ataques prévios.

- Crime não-justificado pela personalidade prévia.

- Crime imotivado e sem premeditação.

- Estudos com EEG compatíveis.

- Alteração do estado de consciência durante o acontecimento.

- Amnésia total ou parcial sobre o crime.

Pode-se observar, nas três proposições, a necessidade de comprovação segura do diagnóstico de epilepsia e da presença de alteração do nível de consciência vígil durante o ato agressivo. Caso contrário, o ato passaria a ser 
analisado quanto aos distúrbios de personalidade, ao nível intelectual e às funções neuropsicológicas. Porém, nenhum deles faz alusão aos quadros psicóticos associados às epilepsias, em que pode não haver alteração do nível de consciência vígil, mas, sim, uma alteração do juízo crítico da realidade comum ${ }^{15}$. Quiçá essa omissão deva-se ao questionamento que hoje se faz de que uma psicose associada à epilepsia pode não estar diretamente correlacionada a esta, mas sim tratar-se-ia de uma outra doença que se instala como comorbidade.

Os resultados de nossa própria experiência clínica vêm ao encontro dos apresentados nesse estudo, ou seja, são raros os episódios de agressividade ictal e, quando ocorrem, apresentam-se em pacientes epilépticos com nível intelectual limitado, com maior dano cerebral, mais transtornos psiquiátricos concomitantes e história prévia de distúrbio de personalidade.

Atualmente, tem-se discutido se os distúrbios mentais que ocorrem no paciente epiléptico são sintomas inerentes à própria epilepsia ou a uma comorbidade, ou seja, um transtorno mental incidindo nesse grupo de pacientes, do mesmo modo que poderia ocorrer com qualquer pessoa da população.

Esse assunto continua controvertido, mas já existem alguns critérios que podem orientar, na prática clínica, uma decisāo diagnóstica.

Diante de episódios comportamentais inusitados. com manifestações agressivas ou não, temos utilizado a "Regra do Bizarro" para auxiliar no diagnóstico diferencial entre crises epilépticas verdadeiras e crises pseudoepilépticas: "toda e qualquer manifestação comportamental humana episódica e bizarra não deve ser entendida como de natureza epiléptica, salvo se:

1. ocorrer em pacientes com outras crises epilépticas inequívocas, como convulsões, automatismos bucomastigatórios associados a estreitamento da consciência;

2. preceder imediatamente uma crise de natureza epiléptica, indiscutível;

3. houver registro eletrencefalográfico concomitante, mostrando descargas epileptiformes. O grau de segurança diagnóstica aumenta progressivamente dos itens 1 ao $3^{\prime \prime 16}$.

Além disso, como descrito anteriormente, Fenton ${ }^{13}$, Delgado-Escueta et al. ${ }^{8}$ e Hindler ${ }^{14}$ também oferecem critérios úteis no diagnóstico diferencial.

Assim, para uma atuação preventiva adequada, devemos estar atentos para os sinais sugestivos de agressividade nos pacientes epilépticos, para oferecer orientação e tratamento medicamentoso, psicológico e familiar, adequados a cada caso.

\section{SUMMARY}

Legal aspects of aggressiveness in epilepsies

Epileptic patients must endure the burden of prejudice, far worse than living with limitations imposed by seizures and treatment themselves. Aggressiveness had been attributed to epilepsy, mainly for law purpose, although no clear relationship could be solidly established in scientific papers until now.

\section{KEYWORDS}

Agressiveness, epilepsy, prejudice, law.

\section{Referências}

1. McLin, WM. \& Boer, HM. Public Perceptions About Epilepsy. Epilepsia, 36(10): 957-959, 1995.

2. Parsonage, $M$. Historical overview of the legislative aspects of epilepsy. In: Canger R, Loeber JN, Castellano F (Eds). Epilepsy and society: realities and prospects. Amsterdam. Excerpta Medica, 1988, 227-30.

3. Horcajadas FA, Aranzadi JJA, Calo JJP. Epilepsia y conductas delictivas. Actas Luso-Esp Neurol Psiquiatr, 23(5):235-240, 1995.

4. Manzano JM, Salamero C, Terron Y, Ledesma A. Variedades de la conducta agresiva interictal en pacientes epilépticos. An Psiquiatria, 7:279-281, 1991.

5. Rodin E. Psychomotor epilepsy and agressive behavior. Arch Gen Psychiatry, 28:210-213, 1973.

6. Gunn J. Criminal behavior and mental disorder. Br $J$ Psychiatry, 130:317-329, 1977.

7. Herzberg JL \& Fenwick PCB. The aetiology of agression in temporal-lobe epilepsy. Br J Psychiatry, 153:50-55, 1988.

8. Delgado-Escueta $A V$, Mattson $R H$, King $L$ e col. The nature of agression during epileptic seizures. N Engl J Med, 305:711716, 1981.

9. Borum R \& Appelbaum K. Epilepsy, Agression, and Criminal Responsibility. Psychiatric Services, 47(7):762-763, 1996.

10. Devinsky $O \&$ Bear $D$. Varieties of agressive behavior in temporal lobe epilepsy. American Journal of Psychiatry, 141:651-656, 1984.

11. Mendez MF, Doss RC, Taylor JL. Interictal violence in epilepsy. Relationship to behavior and seizures variables. J Nerv Ment Dis, 181:566-569, 1993.

12. Fenwick P. Agression and epilepsy. In: Devinsky $O$ \& Theodore WH. Epilepsy and Behavior. New York, Ed. WileyLiss, 1991.

13. Fenton GW. Epilepsy and automatism. Br J Hosp Med, 7:5764,1972

14. Hindler CG. Epilepsy and violence. Br J Psychiatry, 155:246$249,1989$.

15. Savard G, Andermann F, OLivier A, Rémillard GM. Postictal Psychosis After Partial Complex Seizures: A Multiple Case Study. Epilepsia, 32(2):225-231, 1991.

16. Campos CJR. Aspectos práticos e tratamento das Epilepsias. In: Ramos OL. \& Rothschild HA (Eds.). Atualizaçöes Terapêuticas, $19^{4}$ ed., Ed. Artes Médicas, São Paulo, Brasil, 1999. p. 756-759.

\section{Endereço para correspondência}

Universidade Federal de São Paulo

Rua Pedro de Toledo, 655 - Vila Clementino

CEP 04039-030 - Sāo Paulo SP

e-mail: cjcamp@ibm.net 